\title{
Planetary Health: Are We Part of the Problem or Part of the Solution?
}

\author{
Monica Gagliano 1,2,3 \\ 1 Sydney Environment Institute, The University of Sydney, Camperdown, NSW 2006, Australia; \\ monica.gagliano@uwa.edu.au \\ 2 Centre for Evolutionary Biology, School of Biological Sciences, The University of Western Australia, \\ Crawley, WA 6009, Australia \\ 3 inVIVO Planetary Health, The Worldwide Universities Network (WUN), West New York, NJ 07093, USA
}

Received: 14 September 2018; Accepted: 25 September 2018; Published: 28 September 2018

check for updates

\begin{abstract}
Planetary health, formally defined as the interdependent vitality of all natural and anthropogenic ecosystems-social, political, and otherwise-is a vast concept that has now entered the scientific lexicon. The problems associated with planetary ill-health-biodiversity losses, climate change, environmental degradation, and other problems of so-called "anthropocene syndrome" —are considered so enormous that they can immobilize us; we may feel environmental guilt, but that alone cannot save us or the planet. What is missing is environmental empathy, the nurturance of our capacity to recognize the planet and its many life forms as more than elusive entities to be objectified. Although experts in planetary health have called for a more sophisticated understanding of the psychological connections between humans and the natural world, these appeals are almost exclusively cordoned off from the taboos of science; applying concepts of "self" to non-human animals, and especially non-mammals, are generally proscribed. Here, I will personalize the planetary health concept by describing my research-based endeavors on the Great Barrier Reef-experiences that would change my scientific career and personal life forever. The small damselfish, Pomacentrus amboinensis, became the teacher; the student-in-me departed the reef with an education in environmental empathy, and a greater understanding of the urgency with which we must alter our teaching in ecology and other branches of science. Planetary health as a unifying, multidisciplinary effort generally lacks a narrative perspective in academia; I am hopeful that others will share their narrative perspectives and, in doing so, foster the growth of environmental empathy.
\end{abstract}

Keywords: planetary health; ecosystems; climate change; coral reef bleaching; Anthropocene; Environmental Guilt; Environmental Empathy

\section{Introduction}

In November 2015, the eminent journal Nature reported on a special event. It was the 21st meeting of the United Nations on Climate Change in Paris, where representatives from several nations gathered to talk about the intractable "climate problem". After two weeks of heated negotiations and a great deal of caffeine consumption, the meeting resulted in a historic global pledge, namely to adopt international measures in order to reduce greenhouse-gas emissions so as to curb global warming to below $2{ }^{\circ} \mathrm{C}$. Six months later, the same journal reported about the Great Barrier Reef undergoing the most severe bleaching event in its history, as a result of temperatures unremittingly creeping upwards. A year later, Nature reported, again, on the "coral crisis", triggered by warming oceans, right at the time when kilometric aerial surveys were revealing the unfolding of yet another severe bleaching event on the world's most famous coral reef. Reef scientists desperately called for an immediate reduction of greenhouse-gas emissions for a chance to save the reef from dying. While scientists and economists 
together warned that in order to keep us below the $2{ }^{\circ} \mathrm{C}$ mark, no new coal plants could be built from then on (unless they have zero emissions), the Commonwealth Government of Australia was busy issuing a lease for a new coalmine in Queensland, the biggest coalmine in history, estimated to generate about five billion tonnes of greenhouse-gas emissions and to cost Australian taxpayers billions of dollars in subsidies. Aside from the fact that the mine lacks economic viability and its approval is contrary to public interest, if built, the increased shipping and dredging activity would directly cause irreparable devastation across the world's most famous reef. This entire saga is, to say the least, puzzling. The reef is not dying because of climate change. The reef, and more generally the planet, is being killed by our pathological indifference. The question is why? Here, I will share a personal story of two seeds, and how we may avoid repeating the past and instead, truly move into a new planetary future.

\section{In the Eye of the Beholder: A Preamble}

Everything we know about the world comes to us through our senses. Sensing and making sense of this huge amount of information so that one's behavior is well attuned to one's circumstances are crucial challenges, as they require a close match between ones's perception and the world. This is what the cognitive system does; it transduces as well as provides feedback on the next moment of perception through a collection of past experiences and expectations of the future. Paradoxically, information about the world is virtually always misperceived, because our past experiences and expectations of the future inescapably color the perception of our current reality. While the cognitive system opportunely remediates the misperception through new (learning) experiences, and by always "updating" the framework of reference we use to perceive the external world, the end result is a representation of the world according to our judgments and biases. Can we "cleanse the doors of perception" as many poets, writers, and musicians have long invited us to do? Ideally, we would want our perception to be clear, but in actuality, we just go about our life with our perceptual doors being pretty grubby. Generally speaking, then, the available choice is about that which supports the formation of judgments or opinions that are evolutionarily and immediately adaptive, by ensuring that life remains variable and changeable. Why? Because an attitude open to change allows space for a "can-do" approach, it sees broader and alternative resolutions on perceived difficulties, and builds psychological and social resources for the future [1].

This optimistic attitude, as well as a sophisticated understanding of human connections to the natural world, are critically important in the context of planetary health (defined recently as the interdependent vitality of all natural and anthropogenic ecosystems-social, political, and otherwise) [2,3]. However, many current environmental discourses pitch a doom-and-gloom scenario, where the causes of our difficulties and problems are portrayed as stable and general. This attitude towards the global environmental challenges that we are currently facing resists change. It incites doubts, denial, and various forms of defensive thinking, and most tragically, generates learned helplessness, a tendency to simply give up, and an acceptance of the status quo (for an in-depth discussion of this topic, see [1]). This is not an adaptive choice. This is certainly not the only choice available to us. Let me illustrate this point by sharing a personal story. 


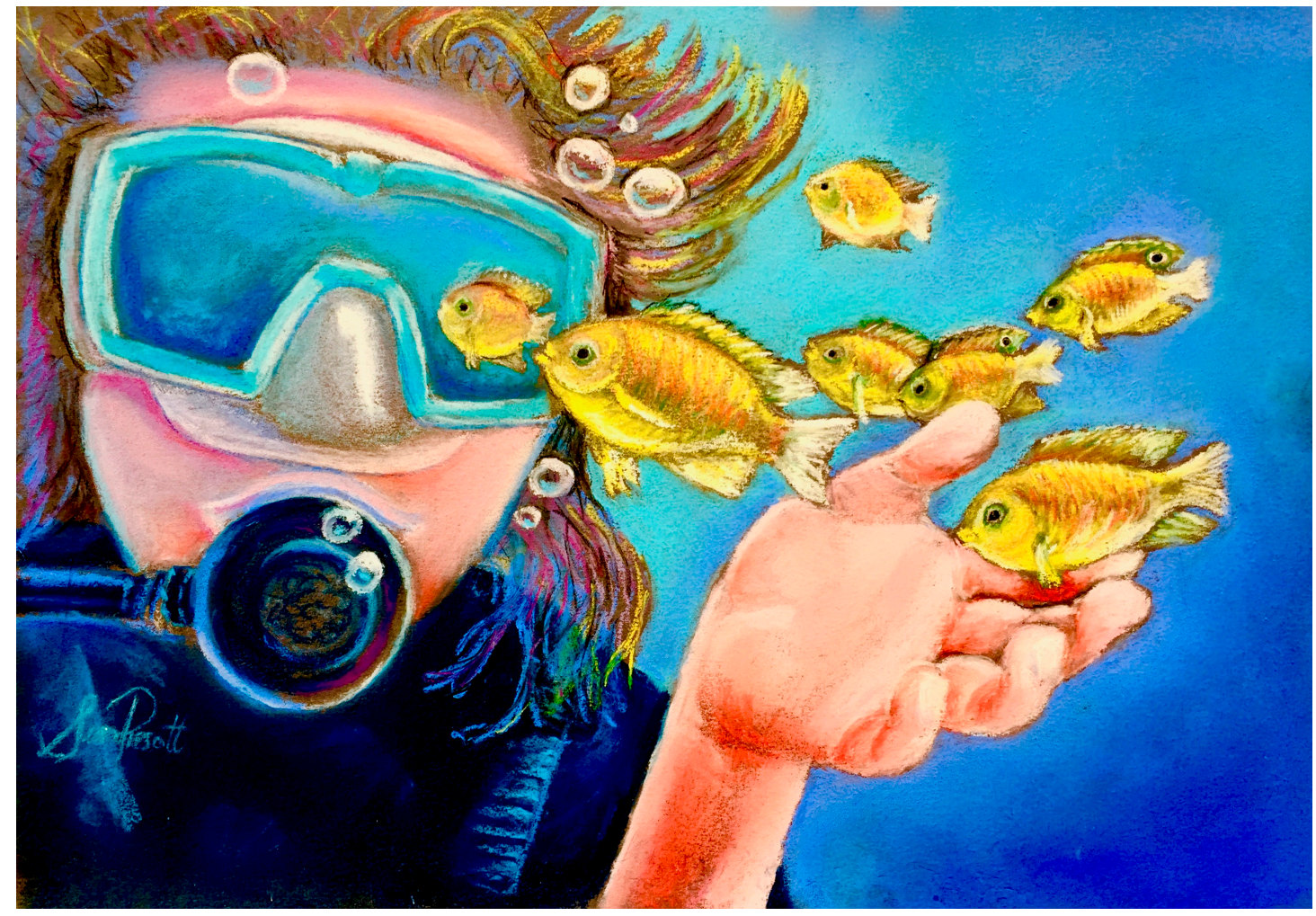

\section{A Story of Two Seeds}

For years, I spent months breathing under the waters of the Great Barrier Reef so as to learn about the private life of a little damselfish species, which science calls Pomacentrus amboinensis. During the warm summer months, I observed females laying eggs in perfect little nooks within the complexity of the reef structure, and males aggressively protecting these benthic nests from egg predators and other intruders. The eggs are under the watchful paternal eye for a few days until hatching. All born females, the tiny larvae will wriggle their way out and away, embarking on a courageous journey far from the reef and out into the open ocean, where mortality is almost absolute. Those few that do survive, swim their way back to the reef under the protective darkness of the new moon, as their diaphanous shapes are transformed into the beautiful catchy colors we love. As time passes, the juveniles audaciously venture further and further out from the safety of their hidey-holes to catch some plankton in the water column, or to compete over new prime spots in the coralline estate. Thanks to the black spot at the rear of the dorsal fin, which does not function-as popular belief would have it-to confuse predators, but instead speaks of their immature reproductive state; these youngsters are tolerated by the dominant males, who allow them to hang around the nest sites and who indirectly protect them from predators. The spot will eventually disappear with age as the juveniles mature into reproductive females, after which some will also change sex to become the dominant males.

But the story is not over; to spice things up, some retain the spot, although they are clearly no longer juveniles anymore. It turns out that these individuals are all mature males who have taken an alternative route (so to speak). By closely resembling the body shape of females and retaining the spot that flags them as immature, these males will sneak their way into the nest sites of the tolerant (albeit oblivious) dominant males in order to contribute to the renewal of the population with minimal effort. The presence of these bright yellow bodies, of different shapes and sizes flickering in the water column like wild confetti feels like a true miracle, a celebration of life. Today, this pondering fills me with a great sense of awe. At the time when this species was the main object of my scientific research, however, their commitment to life did not stop me from fulfilling the murderous necessity of my science. It was like this until the fish ceased to be an anonymous data point, just another fish in 
the agreed sense of the word-the human-centered categorical boundaries asserted through to the Linnaean classification system, which is a fiction brought into being by a particular worldview. No longer an elusive entity void of individuality, but rather a distinct presence that felt much like the kind of "self" that abides within me; the object of my research became a subject for my learning. Then, everything changed.

I remember that morning, vividly. I had been in the water every day for months, monitoring the reproductive output of wild P. amboinensis pairs. Every day, we encountered each other at the edge, where the safety of the reef ended and my hand was stretched out and open. A week into the study, these wild animals snuggled inside my hand as my fingers gently curled around their scaly bodies and then uncurled open again. They knew me, personally. I knew them, one by one. On the last day of the study, I went into the water with the intention of "saying goodbye", before returning in the afternoon to capture and kill them all. That morning, not one was in sight; no one was approaching me, let alone my open hand. A chilling sensation filled me. In that moment, I knew they knew. I felt the blood of all the past killings I had done in the name of my science and a dreadful feeling of guilt arrived in my heart. Frozen and not knowing what to do, I did what I knew. That afternoon, I went back in the water with nets and catch bags and killed them all. I understand now that theirs was an incredible sacrifice that delivered the one gift that would change everything. Because, through the intimacy of our encounter, the time spent being together and being with each other had broken down the taxonomic boundary. In this permeability, a true nakedness had emerged, the kind of vulnerability necessary to establish openness. They taught me empathy. And I never killed again.

It has taken me almost 10 years to recognize that what occurred that day on the reef was one of the most significant events in my career and personal life. Empathy had enabled me to perceive in the fish as "someone" that felt much like the kind of "self" that abides within me (as Barbara Smuts had been able to perceive in her baboons [4], for example). Of course, applying a concept like "self" to a fish or nonhuman other is very controversial (or even taboo) amongst scientists, because we are not sure how to define it and its subjective dimension resists our current scientific methods. In response to this resistance, we simply omit such subjectivity and associated data from our studies, and most poignantly, we ensure that the next generation of field ecologists are suitably trained to do exactly the same. What we fail to recognize is that in the encounter, we too are a subject to the other, and through the encounter, we have entered a shared intersubjective space with the other, one that transcends-without negating - the individuality of the parties. Then, no matter how convincingly we deny or omit the "self" of the other, our reciprocal immediacy is never a neutral (objective) act; no matter how strongly we resist the full "presence" of the other, the encounter always changes us, constantly reimagining both parties anew in a space of interdependence. This capacity to feel our way into the being of another is an inherited skill we all have and can use to be fully present with the world [3]. So, what would the world look like if we chose to teach this to the next generation?

\section{The Moral of the Story}

I called this the story of two seeds-namely, guilt and empathy-because I had been given the opportunity to choose to plant one of them and change my life. In the wider global context, I feel we have arrived at the same point of choice, an opportunity to change the world. So which seed shall we choose to plant in our collective garden? We have zealously been planting environmental guilt, now fashionably referred to as the Anthropocene. To me, this word smells moldy. It smells of patriarchal colonialism, still celebrating our dominion over the environment while religiously confessing our sins of devastation and hoping for redemption. But environmental guilt cannot save us, or the planet. Environmental psychologists tell us that guilt is an emotion that only works when people are faced with "small" issues. When the challenge is perceived to be too big-and our current task is of planetary proportions-guilt overwhelms and immobilizes us to be in a state of hopelessness and helplessness. Just as I did with my fish, we freeze and end up doing what we already know, repeating past actions that have caused the very circumstances we are trying to resolve, and thus not allowing us to move into 
a new future. To choose guilt is to plant the seed that ensures that the individuality of the "other"-in the context of my story, the fish, and in the bigger story, the planet-remains an elusive entity, an objectification that is central to the lack of empathy and that is essential to our reckless exploitation. Yet, we can plant and nurture the other seed, the seed of environmental empathy. Empathy is a seed of wisdom, central to our human capacity for true care, and it is essential to our creative inspiration. To choose empathy is to plant the seed that ensures we encounter the "other", who is constantly beckoning us to open fearlessly, and discover who we are. Just like in my own story, empathy is the inspiring seed that changes everything. By making us available to real change within and out, planetary wellbeing is the inevitable outcome. This brilliant turning point is only one little seed away.

Declaration: This presentation is partly based on material found here: http://sydney.edu.au/environmentinstitute/blog/in-the-eye-of-the-beholder-a-personal-story-of-two-seeds / and in the author's trade paperback, Thus Spoke the Plant: A Remarkable Journey of Groundbreaking Scientific Discoveries and Personal Encounters with Plants. North Atlantic Books (November 2018). The associated image was created by Dr. Susan L. Prescott, inspired by photographs provided by Dr. Monica Gagliano.

Conflicts of Interest: The author declares no conflict of interest.

\section{References}

1. Clayton, S.; Myers, G. Conservation Psychology: Understanding and Promoting Human Care for Nature; Wiley-Blackwell: Chichester, UK, 2015.

2. Prescott, S.L.; Logan, A.C. Larger than life: Injecting hope into the planetary health paradigm. Challenges 2018, 9, 13. [CrossRef]

3. Prescott, S.L.; Logan, A.C.; Albrecht, G.; Campbell, D.E.; Crane, J.; Cunsolo, A.; Holloway, J.W.; Kozyrskyj, A.L.; Lowry, C.A.; Penders, J.; et al. The Canmore Declaration: Statement of Principles for Planetary Health. Challenges 2018, 9, 31. [CrossRef]

4. Smuts, B.B. Encounters with animal minds. J. Consciousness Stud. 2001, 8, 293-309. 